\title{
A thymosin beta-4 is involved in production of hemocytes and immune defense of Hong Kong oyster, Crassostrea hongkongensis
}

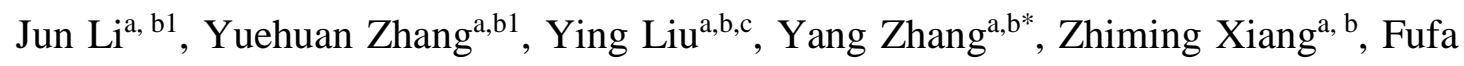
$\mathrm{Qu}^{\mathrm{a}, \mathrm{b}}$, Ziniu $\mathrm{Yu}^{\mathrm{a}, \mathrm{b}^{*}}$

a Key Laboratory of Tropical Marine Bio-Resources and Ecology, Guangdong Provincial Key Laboratory of Applied Marine Biology, South China Sea Institute of Oceanology, Chinese Academy of Sciences, 164 West Xingang Road, Guangzhou 510301, China

b South China Sea Bio-Resource Exploitation and Utilization Collaborative Innovation Center, China

${ }^{\mathrm{c}}$ University of Chinese Academy of Sciences, 19A Yuquan Road, Beijing 100049, China

Running title: A thymosin beta-4 from Hong Kong oyster

*Correspondence:

South China Sea Institute of Oceanology, Chinese Academy of Sciences, 164 West Xingang Road, Guangzhou 510301, China. Tel \& Fax: +86 20 8910-2507; E-mail: carlzyu@scsio.ac.cn; yzhang@scsio.ac.cn

${ }^{1}$ These authors contributed equally to this work. 


\section{Abstract}

Thymosin beta-4 (T $\beta 4)$ is a ubiquitous protein with multiple and diverse intracellular and extracellular functions in vertebrates. In this study, the full-length cDNA of $T \beta 4$ was cloned and identified in Crassostrea hongkongensis, designated as ChTß4. The full-length cDNA of ChT $\beta 4$ consists of $499 \mathrm{bp}$ with an open reading frame of $129 \mathrm{bp}$ encoding a 41 amino acid polypeptide. SMART analysis indicated that there is one thymosin domain and a highly conserved actin-binding motif (18LKKTET23) in ChT $\beta 4$. In vivo injection of recombinant ChT $\beta 4$ protein could significantly increase total hemocytes count in oysters, and knockdown of the expression of ChTB4 resulted in a significant decrease in the circulating hemocytes. Tissue distribution analysis revealed a ubiquitous presence of ChT $\beta 4$, with the highest expression in hemocytes. The upregulated transcripts of ChTB4 in response to bacterial challenge and tissue injury suggest that ChT $\beta 4$ is involved in both innate immunity against pathogen infection and wound healing. Moreover, bacteria-clearance experiment showed ChT $\beta 4$ could facilitate the clearance of injected bacteria in oysters. In vivo injection with ChT $\beta 4$ resulted in reduction of the intracellular ROS in hemocytes, which was associated with increased expression of antioxidant enzymes $\mathrm{Cu} / \mathrm{Zn}$ superoxide dismutase (SOD), Catalase, and Glutathione Peroxidase (GPX) by pre-treatment with ChT $\beta 4$. These results suggest that ChT $\beta 4$ is a thymosin beta- 4 homologue and plays a vital role in the immune defense of $C$. hongkongensis.

Keywords: Crassostrea hongkongensis; thymosin beta-4; total hemocytes count; antioxidant enzymes; 


\section{Introduction}

Thymosins, initially isolated from calf thymus, are a family of ubiquitous intracellular proteins with molecular mass ranging from 1 to $15 \mathrm{kDa}$ (Goodall et al., 1986). This family is divided into three main groups based on their isoelectric points: $\alpha$-thymosins below $\mathrm{pH} 5.0, \beta$-thymosins between $\mathrm{pH} 5.0$ and 7.0 , and $\gamma$-thymosins above pH 7.0 (Hannappel and Huff, 2003). Among these, $\beta$-thymosins are acidic peptides with a molecular mass of $5 \mathrm{kDa}$ and share high homology among members. The $\beta$-thymosins are acknowledged as G-actin sequestering peptides and more than $15 \beta$-thymosins have been reported (Huff et al., 2001). Thymosin $\beta 4$ (T $\beta 4$ ), a highly conserved member of the $\mathrm{b}$ thymosin family, is the most abundant member in most cell types (Hannappel and van Kampen, 1987). Given its abundance and numerous cellular functions, thymosin $\beta 4$ has drawn great attention since its discovery (Yu et al., 1993).

First identified from a cytokine-like activity, $\mathrm{T} \beta 4$ is a multi-functional protein with diverse physiological roles, including cell migration, tumor metastasis, attachment and spreading of endothelial cells, stimulation of hormone releasing factor secretion and cerebellar development (Emmanouilidou et al., 2013; Gomez-Marquez and Anadon, 2002; Kang et al., 2011; Lee et al., 2009; Li et al., 2007b; Malinda et al., 1997; Rebar et al., 1981; Selmi et al., 2012). Apart from these functions, T $\beta 4$ was found to play a fundamental role in host defense (Nemolato et al., 2010). Moreover, human thymosin $\beta 4$ is an important antimicrobial protein in platelets (Tang et al., 2002). It also promoted full-thickness cutaneous wound healing in BALB/c mice (Li et al., 2007a; Tang et al., 2002). T $\beta 4$ blocked nuclear translocation of the NF-kappaB 
p65 subunit in NF-alpha-stimulated corneal epithelial cells, and subsequently inhibited the activation of NF-kappaB in TNF-alpha-stimulated cells (Sosne et al., 2007). T $\beta 4$ sulfoxide acts as a signal to inhibit an inflammatory response. In vitro, T $\beta 4$ sulfoxide inhibited neutrophil chemotaxis, and in vivo, the oxidized peptide, but not the native form, was a potent inhibitor of carrageenan-induced edema in the mouse paw (Young et al., 1999). Lee et al. suggested that T $\beta 4$ was a key activator of NK cell cytotoxicity. T $\beta 4$ prevents $\mathrm{H}_{2} \mathrm{O}_{2}$-induced profibrotic changes by selectively targeting and upregulating catalase, $\mathrm{Cu} / \mathrm{Zn}-\mathrm{SOD}$ and $\mathrm{Bcl}_{2}$ in the myocardium (Kumar and Gupta, 2011). T $\beta 4$ may ultimately enhance the immune response during viral infection and modulate the development of T lymphocytes in Cyprinus carpio L (Xiao et al., 2015). All these studies indicate that T $\beta 4$ plays important roles in the physiological regulation of immunity.

In comparison to the extensive studies in vertebrates, the knowledge of T $\beta 4$ from invertebrates, especially mollusks, is fairly limited. The first invertebrate $\beta$-thymosin ortholog was isolated from Drosophila, which contains three thymosin domains and plays a major role in axonal growth during brain metamorphosis (Boquet et al., 2000). In Caenorhabditis elegans, tetra thymosin beta is of crucial importance at specific developmental stages requiring actin polymerization (Herrmann et al., 2005). Two types of $\mathrm{T} \beta$ homologs isolated from Eriocheir sinensis induced human cell proliferation and played a role in pathogen stimulation and injury challenge (Gai et al., 2009). Recent studies indicated that the T $\beta$ homolog of abalone was involved in the immune response of Haliotis diversicolor supertexta ( $\mathrm{Wu}$ and $\mathrm{Wu}, 2009), H$. discus 
discus (Kasthuri et al., 2013) and Crassostrea gigas (Nam et al., 2015). However, to our knowledge, the $T \beta 4$ gene has not been characterized, nor its function studied, in the Hong Kong oyster. To better understand the role of T $\beta 4$ in innate immunity of Hong Kong oyster, C. hongkongensis, the first T $\beta 4$ homolog was identified and characterized in the present study.

\section{Materials and methods}

\subsection{Oysters, bacterial and injury challenge}

Hong Kong oysters, C. hongkongensis (two years old, shell height $10.00 \mathrm{~cm}$ $\pm 0.05 \mathrm{~cm}$ ), were obtained from Zhanjiang, Guangdong Province, China and acclimated with aerated sand-filtered seawater in the laboratory for 2 weeks before the experiment. The oysters were fed twice daily with Tetraselmis suecica and Isochrysis galbana.

The bacterial challenge experiment was performed according to our previous work (Zhang et al., 2011). Oysters received an injection of $100 \mu \mathrm{L}$ (approximately $1 \times 10^{8}$ bacterial cells) of Vibrio alginolyticus (Gram-negative bacteria), Staphylococcus haemolyticus (Gram-positive bacteria) or PBS as a control. After injection, the oysters were returned to the seawater tanks and 5 individuals were randomly sampled at 3, 6, 12, 24, 48 and $72 \mathrm{~h}$ post-injection. For injury challenge, 120 oysters were used in the wounding experiment and were randomly divided into experimental and control groups. A piece of tissue approximately $1 \mathrm{~cm}$ length and 0.2 $\mathrm{cm}$ in depth was removed from the mantle of each oyster with a clean knife. All injuries were induced at the same position in each oyster and untreated oysters were 
used as the control. After injury, the oysters were returned to seawater tanks and 5 individuals were randomly sampled at 3, 6, 12, 24 and $48 \mathrm{~h}$ post-injection. The hemolymph was collected and centrifuged at $700 \mathrm{~g}, 4{ }^{\circ} \mathrm{C}$, for $10 \mathrm{~min}$ to harvest hemocytes for RNA preparation. To analyze RNA expression patterns, total RNA was extracted from the gills, mantles, adductor muscles, digestive glands, gonads, and hemocytes of three healthy animals.

\subsection{Cloning the full-length ChTß4}

The partial cDNA sequences of ChT $\beta 4$ were obtained from the Hong Kong oyster transcriptional database. To obtain the full-length cDNA of ChTß4, the SMART $^{\mathrm{TM}}$ RACE cDNA amplification kit (Clontech, Japan) was used, following our previous description (He et al., 2011). The primers used in this study are listed in Table 1. The target PCR products were cloned to pGEM-T Easy Vector (Promega, USA) and the plasmids were sequenced using universal primers with the BigDye-Terminator kit on an ABI PRISM 3730 Genetic Analyzer (Perkin Elmer, USA). The full-length cDNA sequences were obtained by combining the 3 '- and 5'-end sequences.

\subsection{RNA isolation and cDNA synthesis}

Total RNAs were extracted from tissues (hemocytes, digestive gland, heart, gill, mantle, adductor muscle, and gonad) with TRIzol Reagent (Invitrogen, USA), according to the manufacturer's protocol. The integrity of RNA was verified by agarose gel electrophoresis. Then, 1000 ng of total RNA was used to perform reverse transcription (RT) using the PrimeScript ${ }^{\mathrm{TM}}$ RT Reagent Kit Ver.2.0 (TaKaRa, Japan) 
for cDNA synthesis, following the manufacturer's instructions.

\subsection{Bioinformatics analysis of ChTß4}

The ChT $\beta 4$ sequence was analyzed using the BLAST algorithm at NCBI (http://www.ncbi.nlm.nih.gov/blast) and the Expert Protein Analysis System (http://www.expasy.org/). Multiple sequence alignments were generated using ClustalX (version 1.81), and protein motifs were predicted with SMART (http://smart.embl-heidelberg.de). A neighbor-joining (NJ) phylogenetic tree was constructed based on the full-length amino acid sequences of known T $\beta$ s using the MEGA4.0 package. The reliability of branching was tested using bootstrap re-sampling (with 1000 pseudo-replicates).

\subsection{Recombinant expression of ChTß4}

The ChT $\beta 4$ open reading frame (ORF) was amplified with specific primers (Table 1). The PCR fragment was digested with the restriction enzymes BamH I and Hind III and then cloned into the pET-28a expression vector. Positive colonies were verified by DNA sequencing, and the confirmed recombinant plasmids were transformed into Escherichia coli BL21 (DE3). The parent vector (pET-28a) without any insert fragment was used as the negative control. Positive transformants were incubated in LB medium with $100 \mathrm{mg} / \mathrm{mL}$ ampicillin at $37{ }^{\circ} \mathrm{C}$ with shaking at 200 rpm. When the culture media reached an OD600 of 0.5-0.6, the cells were incubated for 4 additional hours after induction with IPTG at a final concentration of $1 \mathrm{mM}$. The recombinant ChT $\beta 4$ protein containing a $6 \times$ His-tag was purified according to the manufacturer's instructions. The purified proteins were analyzed using $12 \%$ sodium 
dodecyl sulfate-polyacrylamide gel electrophoresis (SDS-PAGE).

\subsection{In vivo injection of ChTß4 and Circulating hemocytes count}

Oyster adductor muscle were injected with $100 \mu \mathrm{L}$ recombinant ChT $\beta 4$ (100 $\mathrm{ng} / \mu \mathrm{L}$ ) or BSA as a control, as described previously (Li et al., 2013). 3, 6, 12, and 24 $\mathrm{h}$ after injection, the oysters were randomly sampled and the total hemocytes count (THC) was determined $(\mathrm{N}=10)$. THC were performed to determine the total number of hemocytes per milliliter of oyster hemolymph. $50 \mu \mathrm{L}$ of the hemolymph-anticoagulant mixture was counted using a hemocytometer (Malassez chamber) and examined by light microscopy, as previously reported (Sritunyalucksana et al., 2005). All hemocytes in both the top and bottom fields of the hemocytometer were counted and every sample was measured three times.

\subsection{Silencing of ChTß4 and Circulating hemocytes count}

Silencing of ChT $\beta 4$ in oyster was carried out by injection with dsRNA as previously described (Choi et al., 2013). The dsRNA sequences for ChT $\beta 4$ and EGFP (dsChT $\beta 4$ and dsEGFP, respectively) were prepared with T7 RiboMAX Express RNAi System (Promega, USA) as manufacturer's instructions. For RNAi, each oyster was injected with $100 \mu \mathrm{g}$ dsRNA (dsChT $\beta 4$ or dsGFP) into the adductor muscle. Injection was repeated after $24 \mathrm{~h}$. Oysters injected with dsEGFP were used as a control group. After 7 days post injected, the RNAi efficiency was assessed by qRT-PCR from the hemocytes of five randomly individuals. Total hemocytes count (THC) were measured using hemocytometer as described above.

\subsection{Transcriptional analysis of ChTß4 by qRT-PCR}


The tissue-specificity of ChTß4 expression in oysters and the temporal expression in hemocytes after challenge with bacterial and injury were determined by qRT-PCR. The EFla gene, a constitutively expressed gene, was employed as an internal control. The primers used for qRT-PCR are listed in Table 1. qRT-PCR was performed using the SYBR Green PCR mastermix on the LightCycler 480 (Roche, USA). The reaction volume was $20 \mu \mathrm{L}$, including $10 \mu \mathrm{L}$ of $2 \times$ Master Mix (Roche, USA), $0.4 \mu \mathrm{L}$ of each of the forward and reverse primers $(10 \mathrm{mM}), 1 \mu \mathrm{L} c \mathrm{cNA}$, and 8.2 $\mu \mathrm{L}$ of PCR-grade water. The qRT-PCR cycling program was as follows: initial denaturation at $95^{\circ} \mathrm{C}$ for $3 \mathrm{~min}$; followed by 45 amplification cycles of $95^{\circ} \mathrm{C}$ for $15 \mathrm{~s}$, $55{ }^{\circ} \mathrm{C}$ for $15 \mathrm{~s}, 72{ }^{\circ} \mathrm{C}$ for $10 \mathrm{~s}$; and $85{ }^{\circ} \mathrm{C}$ for $20 \mathrm{~s}$ for signal collection in each cycle. A melting curve analysis was performed at the end of each PCR reaction to confirm the specificity of the amplicons. Each sample was assayed in triplicate along with the internal control, and negative controls were included to assess genomic contamination. The PCR efficiencies for the target and reference genes (EFla) were approximately equal, and the relative expression level of ChT $\beta 4$ was calculated based on the $2^{-\Delta \Delta \mathrm{Ct}}$ method (Livak and Schmittgen, 2001).

\subsection{Bacteria clearance assay}

The bacteria-clearance assay was performed as described previously with slight modifications(Wang et al., 2009). Briefly, purified recombinant ChT $\beta 4(100 \mathrm{mg} / \mathrm{mL})$ was incubated with $V$. alginolyticus $\left(1 \times 10^{8}\right)$ at $28{ }^{\circ} \mathrm{C}$ for $30 \mathrm{~min}$ with gentle mixing. The oysters were divided into two groups with 30 individuals in each group. $100 \mu 1$ of the recombinant ChT $\beta 4$-coated bacteria (which included a total of $1 \times 10^{8} \mathrm{cfu}$ of $V$. 
alginolyticus together with recombinant ChT $\beta 4)$ or control $\left(1 \times 10^{8} \mathrm{cfu}\right.$ of $V$. alginolyticus together with BSA) were injected into the adductor muscle each oyster. $500 \mu \mathrm{l}$ of hemolymph of each oyster were collected from pericardial cavity through the adductor muscle at $3,6,12$, and $24 \mathrm{~h}$ post-injection. After gradient dilution, the hemolymph was plated on LB agar plates overnight at $37^{\circ} \mathrm{C}$ to count the numbers of bacteria. The percentage of remnant bacteria (the number of bacteria at different time point/the number of bacteria in at $3 \mathrm{~h}$ after injection $\times 100 \%$ ) was determined. The assay was repeated in triplicate.

\subsection{Quantification of intracellular ROS and expression of antioxidant enzymes}

\section{under oxidative stress}

ROS were measured with the non-fluorescent probe $2^{\prime}, 7^{\prime}$ - dichlorofluorescein diacetate (DCFH-DA), as previously described (Tian et al., 2006). In brief, ChT $\beta 4$ - or BSA-treated hemocytes were incubated with $10 \mu \mathrm{mol} / \mathrm{L}$ DCFH-DA in the dark at the ambient temperature for $20 \mathrm{~min}$, according to the manufacturer's instructions. DCFH-DA is membrane permeable and it is intracellularly deacetylated to form 2', 7'-dichlorofluorescein (DCFH), a non-green fluorescent product. In the presence of ROS, DCFH is oxidized to the fluorescent product DCF, which is trapped inside the cells. After incubation, the hemocytes were washed three times with PBS and the fluorescence was immediately determined by flow cytometry (BD FACSCalibur).

Primary cultured hemocytes were prepared from pericardial cavity of Hongkong oyster and were plated at a field density of $2 * 10^{4}$ cells per $\mathrm{cm}^{2}$ on $60 \mathrm{~mm}$ dishes at $25{ }^{\circ} \mathrm{C}$. ChT $\beta 4$ was pretreated $2 \mathrm{~h}$ before the $\mathrm{H}_{2} \mathrm{O}_{2}$ challenge at a final concentration of 
$1 \mu \mathrm{g} / \mathrm{mL}$ which was based on the previous report (Kumar and Gupta, 2011). Mixed primary cultures of hemocytes ( $3 \mathrm{~mL}$ in each plate) were challenged by adding $50 \mu \mathrm{M}$ $\mathrm{H}_{2} \mathrm{O}_{2}$. Hemocytes were harvested at $3,6,12$, and $24 \mathrm{~h}$ after challenge for RNA isolation. Expression levels of antioxidant enzymes $\mathrm{Cu} / \mathrm{Zn}$ SOD, Catalase and GPX were investigated by qRT-PCR. The primers used to amplify antioxidant enzymes products are listed in Table 1. The relative expression level was calculated based on the $2^{-\Delta \Delta \mathrm{Ct}}$ method as mentioned above.

\subsection{Statistical analysis}

The data are presented as the means \pm S.D. The significant differences between groups were analyzed by one-way ANOVA followed by Turkey's multiple comparison tests using the SPSS software package.

\section{Results}

\subsection{Bioinformatics analysis of the ChTß4 gene}

The full-length cDNA of ChTB4 was obtained and submitted to the NCBI under GenBank accession number KT336318. The complete cDNA sequence of ChTB4 is composed of $499 \mathrm{bp}$ with an open reading frame of 129 bp encoding a 41 amino acid polypeptide with a predicted molecular weight of $4.7 \mathrm{kDa}$ and a $\mathrm{pI}$ of 6.21 . The polyadenylation signal AATAAA is located upstream of the poly (A) tail (Fig 1). SMART software analysis revealed one thymosin domain in ChT $\beta 4$ and a highly conserved actin-binding motif (18LKKTET23), which is characteristic of the $\beta$-thymosin protein family.

Multiple sequence alignment showed a high conservation between ChT $\beta 4$ and its 
ortholog. ChT $\beta 4$ has $64.4-75.6 \%$ identity with its homologs, from mollusks to mammals. In addition, phylogenetic analysis showed that all ChT $\beta 4$ homologs could be grouped into vertebrate and invertebrate clusters, with ChT $\beta 4$ belonging to the invertebrate group (Fig 1).

\subsection{ChTß4 stimulated an increase in circulating hemocytes}

To determine the effect of ChT $\beta 4$ on the total hemocytes count in oysters, recombinant ChT $\beta 4$ was purified at its predicted molecular weight (Fig 2) and administered to oyster adductor muscles. The total hemocytes were measured using a hemocytometer (Malassez chamber) and examined on a light microscope. After ChT $\beta 4$ injection, the hemocytes concentration significantly increased at $6 \mathrm{~h}$ and peaked at $12 \mathrm{~h}$ compared to the control group. At $12 \mathrm{~h}$ post-injection, the average total hemocytes count $(\mathrm{THC})$ was $6.33 \pm 0.63 \times 10^{6}(\mathrm{~N}=10)$ cells $/ \mathrm{mL}$ in the ChT $\beta 4$ group and $3.42 \pm 0.43 \times 10^{6}$ cells $/ \mathrm{mL}$ in the control group (Fig 3). Afterwards, THC declined gradually and recovered to the original level at $24 \mathrm{~h}$.

\subsection{Silencing of ChTB4 expression decreased total hemocytes counts}

To further characterize the role of $\mathrm{ChT} \beta 4$ in the total hemocytes counts of oysters, a ChT $\beta 4$ knock-down experiment was performed. The efficiency of RNAi was detected by qRT-PCR. The results showed that the expression of ChT $\beta 4$ was significantly decreased in the ChT $\beta 4$-dsRNA injection group. While no significant change was found in the EGFP-dsRNA or PBS injection group. At 7 days post-injection, oysters injected with ChT $\beta 4$-dsRNA showed significantly lower THC than those injected with EGFP-dsRNA or PBS group (Fig 4). Our data demonstrate 
that ChT $\beta 4$ is involved in the production of hemocytes of oysters.

\subsection{ChTß4 tissue distribution and temporal expression under bacterial challenge}

qRT-PCR was used to assess levels of $C h T \beta 4$ mRNA in various tissues. ChT $\beta 4$ mRNA is constitutively expressed in all collected tissues, including hemocytes, gonads, hearts, adductor muscles, mantles, gills, and digestive glands (Fig 5A). The highest expression level is observed in hemocytes, indicating that it plays a vital role in innate immunity. The expression of ChTB4 mRNA in hemocytes after $V$. Alginolyticus and S. haemolyticus challenge remained stable during the first $3 \mathrm{~h}$. The expression level of ChTB4 mRNA significantly increased at $6 \mathrm{~h}$ (V. alginolyticus) and $12 \mathrm{~h}$ (S. haemolyticus) post-injection, both peaking at $24 \mathrm{~h}$ post-injection compared to the control group. From 24 to $72 \mathrm{~h}$ post-injection, the expression of ChTß4 mRNA returned to the original level (Fig 5B).

\subsection{ChTß4 facilitates the clearance of $V$. alginolyticus}

Considering ChT $\beta 4$ could increase the production of hemocytes and enhance innate immune responses against bacterial infection, we hypothesized that ChT $\beta 4$ could facilitate the clearance of $V$. alginolyticus. To prove this hypothesis, a bacteria-clearance assay was performed, through injecting $V$. alginolyticus pre-incubated with recombinant ChT $\beta 4$. At beginning of the first $3 \mathrm{~h}$, the bacteria counts in oyster of ChT $\beta 4$ group and the control group (BSA injected) was indistinctive. However, the remnant bacteria counts in ChT $\beta 4$-injection group were significant less than those in the control group at $6 \mathrm{~h}$ post-injection. Significant difference between the two groups was also observed at $12 \mathrm{~h}$ post-injection, while 
after 24 h no significant difference was observed (Fig 6). These results indicated that ChT $\beta 4$ had effective role in the clearance of $V$. alginolyticus in oyster.

\subsection{ChTß4 inhibits intracellular ROS production and upregulates the expression of antioxidant enzymes under oxidative stress in the oyster}

ROS play an important role in immune defense of oysters. Oyster's hemocytes have been reported to produce reactive oxygen species (ROS). Under this circumstance, we investigated the effect of ChT $\beta 4$ on hemocytes intracellular ROS production using the fluorescent probe DCFHDA, which can be oxidized to the highly fluorescent compound DCF. At $6 \mathrm{~h}$ post-injection, intracellular ROS production of hemocytes was decreased slightly. After ChT $\beta 4$ injection for $12 \mathrm{~h}$, intracellular ROS production of hemocytes was significantly decreased when compared to the control group, showing that ChT $\beta 4$ inhibited intracellular ROS production. As shown in Fig 4, ROS production was decreased by $27 \%$ through treatment with ChT $\beta 4$ (Fig 7).

To evaluate whether ChT $\beta 4$ has anti-oxidation activities in oyster hemocytes, the effect of ChT $\beta 4$ on the expression of antioxidant enzymes was determined (Fig. 8). Significant induction of $\mathrm{Cu} / \mathrm{ZnSOD}$, Catalase, and GPX were observed after administration of recombination protein ChT $\beta 4$ post-treatment. The expression level of Catalase transcripts significantly increased and peaked at $6 \mathrm{~h}$ after ChT $\beta 4$ treatment. As time progressed, the expression level of the gene gradually decreased. In contrast, the $\mathrm{Cu} / \mathrm{ZnSOD}$ mRNA reached the highest expression level at $12 \mathrm{~h}$. No significant change in GPX mRNA level were observed during the first $6 \mathrm{~h}$ of ChT $\beta 4$ treatment, however, the relative expression level of GPX significantly increased at 12 and $24 \mathrm{~h}$ 
after ChT $\beta 4$ treatment, respectively (Fig 8).

\subsection{ChTß4 is involved in wound healing}

In mollusk, the hemocytes are the main cell type involved in wound healing. They remove damaged cells and tissue debris from the wound area by phagocytosis (Ottaviani et al., 1996). During the wound healing, T $\beta 4$ could greatly promote hemocytes migration, which will facilitate the wound healing(Saelee et al., 2013). As a result, a tissue injury experiment was conducted to investigate the potential role of

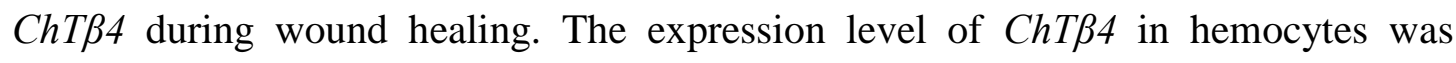
investigated following tissue injury. No significant change in ChTß4 mRNA levels were observed during the first $12 \mathrm{~h}$ of the challenge, however, the relative expression level of ChTß4 increased 3.0-fold compared to the control group at $24 \mathrm{~h}$ after tissue injury(Fig 9).

\section{Discussion}

$\beta$-thymosins are abundant peptides and involved in various physiological functions, including cell migration, ROS production, wound healing, and immune-related processes (Hannappel and Huff, 2003; Kumar and Gupta, 2011; Xiao et al., 2015). Mammalian T $\beta 4$ is the most common and most studied member of the $\beta$-thymosin family, which is found in almost all cells with relatively higher levels in circulating cells (Goldstein et al., 2005). However, the roles and functions of thymosins in mollusks are still poorly understood. Here, we have identified and characterized a T $\beta 4$ gene from the Hong Kong oyster. ChT $\beta 4$ possesses a single thymosin domain, which is required for a protein to be defined as a T $\beta 4$ family 
member. Analysis of ChT $\beta 4$ revealed the existence of a conserved actin binding LKKTET motif, indicating that the conserved key amino acids may retain a conserved function. Multiple alignment and phylogenetic analysis also confirmed that ChT $\beta 4$ shares a high degree of identity with its orthologs in mollusks and vertebrates, consistent with human, mouse and zebrafish $\mathrm{T} \beta 4$ proteins.

The circulating hemocytes of invertebrate are known as "the immune actors" and play a key role in innate immunity responses, including engulfing bacteria via phagocytosis, agglutinating bacteria and producing reactive oxygen species. The concentration of hemocytes, usually called the total hemocytes count (THC), always varies with the presence of exogenous agents in organisms (Wang et al., 2008). In this study, THC increased significantly after ChT $\beta 4$ stimulation. Similar increases in THC or a certain hemocytes sub-population has been reported in crustaceans after $\beta$-thymosin stimulation. In crustaceans, $\beta$-thymosin had a clear but transient effect on the total number of circulating hemocytes, in particular the semigranular cell (Saelee et al., 2013). Moreover, recombinant Eriocheir sinensis $\beta$-thymosin could significantly accelerate the growth of a human hepatocellular carcinoma cell line (Gai et al., 2009). Due to the open circulatory system in the Hong Kong oyster, this elevated hemocytes level may result either from regeneration of hematopoietic tissues, or from surrounding tissue mobilization back into the circulatory system. Although it is still unclear how ChT $\beta 4$ increases THC in oysters, the increased THC might enhance innate immune responses against bacteria infection. To further explore the role of ChT $\beta 4$ in hemocytes production of oysters, in vivo dsRNAi experiment was 
performed in the present study. The THC decreased dramatically after ChT $\beta 4$ knocked-down. All these results indicated that ChT $\beta 4$ play an important role in the production of hemocytes of oysters.

The tissue distribution of ChT $\beta 4$ mRNA and the temporal expression pattern in response to bacterial challenge were determined by qRT-PCR. The ChT $\beta 4$ mRNA was constitutively expressed in various tissues, including hemocytes, gonads, hearts, adductor muscles, mantles, gills, and digestive glands. The ChTß4 transcripts were mostly detected in hemocytes, which are thought to play a central role in the recognition and elimination of foreign pathogens. Similarly, in $H$. discus discus and $H$. diversicolor supertexta, the highest expression of $\beta$-thymosin was observed in hemocytes (Kasthuri et al., 2013; Wu and Wu, 2009). Following V. alginolyticus and $S$. haemolyticus challenge, ChT $\beta 4$ mRNA expression in hemocytes was significantly upregulated from $6 \mathrm{~h}$ and $12 \mathrm{~h}$, respectively, compared to the control, indicating that ChTB4 mRNA was effectively induced by $V$. alginolyticus and S. haemolyticus simulation and probably involved in the interaction between Hong Kong oyster and bacteria. Previous studies reported that thymosin $\beta 4$ was a potential antimicrobial peptide in humans and sea urchins (Schillaci et al., 2012; Tang et al., 2002). In agreement with this observation, the expression of $\beta$-thymosin mRNA in $H$. discus discus, H. diversicolor supertexta, E. sinensis and C. carpio was induced in response to bacterial or viral challenge(Gai et al., 2009; Kasthuri et al., 2013; Wu and Wu, 2009; Xiao et al., 2015). These results suggested that ChT $\beta 4$ could be induced by pathogen infection, and the abundant expression of ChT $\beta 4$ in hemocytes indicates its function 
in the innate immune system of the Hong Kong oyster.

$V$. alginolyticus is an important opportunistic bacterial pathogen for oysters, which may cause mass mortality of these animals. When challenged with $V$. alginolyticus, the transcripts of ChT $\beta 4$ significantly upregulated, indicating its involvement in bacterial infection of oyster. To further investigate the defending role in innate immunity of oysters, $V$. alginolyticus clearance was determined by injecting ChT $\beta 4$. Prior-incubation of bacteria with recombinant ChT $\beta 4$ showed an effective elimination of oysters, suggesting ChT $\beta 4$ could facilitate the clearance of invading bacteria.

Accumulating evidence indicates that ROS serve as critical signaling molecules in cell proliferation, survival and immune response. The generation of cytotoxic ROS is a general protective mechanism in most, if not all, animal species. However, excess ROS may cause damage to the organism. In this study, our data clearly confirmed that ChT $\beta 4$ could significantly inhibit the production of intracellular ROS. On one hand, the removing excessive ROS have potential cytotoxic and carcinogenic effects. On the other hand, the elimination of too much ROS could also destroy the steady-state ROS level, which is important of certain metabolic pathways. The production of these ROS molecules has been associated with antioxidant enzymes in vertebrates as well as in bivalves (Arai et al., 2007; Liu et al., 2014; Yu et al., 2011). Treatment with antioxidant enzymes like SOD and Catalase decrease reactive oxygen species generation and oxidative stress. Consequently, upregulated expression of antioxidant enzymes could reasonably be expected to result in a subsequent decrease 
in ROS production. In the present study, our data clearly confirmed that ChT $\beta 4$ could significantly increase the expression of antioxidant enzymes and meanwhile inhibit the production of ROS. These results are consistent with previous studies that $\mathrm{T} \beta 4$ has been shown to be involved in cellular anti-oxidation activities and inhibit reactive oxygen species (ROS) (Spurney et al., 2010).

Apart from a role in immune defense, a histological study also shows that mollusk haemocytes are involved in wound healing. Emerging evidences indicate that thymosin beta 4 is a novel wound healing agent that promotes tissue repair and decreases inflammation after injury. T $\beta 4$ promotes cardiomyocyte migration, survival, and repair after experimental myocardial infarction, suggesting its potential as a new therapeutic target in the setting of acute myocardial damage (Bock-Marquette et al., 2004). Recombinant human T $\beta 4$ can promote lymphocyte proliferation, differentiation and full-thickness cutaneous wound healing (Li et al., 2007b). Chronic administration of $\mathrm{T} \beta 4$ increased the number of regenerating fibers and could have a potential role in the treatment of skeletal muscle disease in Duchenne muscular dystrophy (Spurney et al., 2010). We therefore examined the expression profile of ChT $\beta 4$ after tissue injury to better understand its physiological function, because the Hong Kong oyster exhibits a high capacity of wound healing. The present study clearly showed that ChTB4 mRNA in hemocytes was strongly upregulated compared with the control group following mantle tissue injury. Similar strong induction of TR4 mRNA expression was observed after injury in porcine species (Ferre et al., 2007). T $\beta 4$ binding to F1-F0 ATP synthase resulted in an increased synthesis of extracellular 
levels of ATP, which is necessary in wound healing (Selmi et al., 2012). During injury, the hemocytes was likely induced to migrate to injured site for wound healing by elevated ChTB4 mRNA. However, further studies, e.g., those using cell migration assay, are needed for confirmation.

Taken together, our studies cloned and identified a $T \beta 4$ cDNA from the Hong Kong oyster. We showed that in vivo injection of recombinant ChT $\beta 4$ protein could significantly increase total hemocytes count in oysters, and silencing of ChT $\beta 4$ could reduce the circulating hemocytes. The upregulated transcript levels of ChT $\beta 4$ in response to bacterial challenge further indicate that ChT $\beta 4$ is involved in innate immunity against pathogen infection. ChT $\beta 4$ could facilitate the clearance of injected bacteria in oysters. It can also inhibit ROS production and induce the expression of antioxidant enzymes. The present study contributes to a better understanding of the complex molecular mechanisms of host defense in mollusk.

\section{Acknowledgments}

This work was supported by the Joint Funds of NSFC-Guangdong of China (U1201215), National Science Foundation of China (No. 31502193), Guangdong Natural Science Foundation (No. 2014A030310402) and Science and Technology Planning Project of Guangdong Province, China(No. 2014B030301064). We also thank Dr. JianLin Zhang for his kind assistance with the flow cytometry analysis.

\section{References:}

Arai, M., Shibata, Y., Pugdee, K., Abiko, Y., Ogata, Y., 2007. Effects of reactive 
oxygen species (ROS) on antioxidant system and osteoblastic differentiation in MC3T3-E1 cells. IUBMB Life 59, 27-33.

Bock-Marquette, I., Saxena, A., White, M.D., Dimaio, J.M., Srivastava, D., 2004. Thymosin beta4 activates integrin-linked kinase and promotes cardiac cell migration, survival and cardiac repair. Nature 432, 466-472.

Boquet, I., Boujemaa, R., Carlier, M.F., Preat, T., 2000. Ciboulot regulates actin assembly during Drosophila brain metamorphosis. Cell 102, 797-808.

Choi, S.H., Jee, B.Y., Lee, S.J., Cho, M.Y., Kim, J.W., Jeong, H.D., Kim, K.H., 2013. Effects of RNA interference-mediated knock-down of hypoxia-inducible factor-alpha on respiratory burst activity of the Pacific oyster Crassostrea gigas hemocytes. Fish Shellfish Immunol 35, 476-479.

Emmanouilidou, A., Karetsou, Z., Tzima, E., Kobayashi, T., Papamarcaki, T., 2013. Knockdown of prothymosin alpha leads to apoptosis and developmental defects in zebrafish embryos. Biochem Cell Biol 91, 325-332.

Ferre, P.J., Liaubet, L., Concordet, D., SanCristobal, M., Uro-Coste, E., Tosser-Klopp, G., Bonnet, A., Toutain, P.L., Hatey, F., Lefebvre, H.P., 2007. Longitudinal analysis of gene expression in porcine skeletal muscle after post-injection local injury. Pharm Res 24, 1480-1489.

Gai, Y., Zhao, J., Song, L., Wang, L., Qiu, L., Ning, X., Zheng, X., Zhang, Y., Mu, C., Li, L., 2009. Two thymosin-repeated molecules with structural and functional diversity coexist in Chinese mitten crab Eriocheir sinensis. Dev Comp Immunol 33, 867-876. 
Goldstein, A.L., Hannappel, E., Kleinman, H.K., 2005. Thymosin beta4: actin-sequestering protein moonlights to repair injured tissues. Trends Mol Med 11, 421-429.

Gomez-Marquez, J., Anadon, R., 2002. The beta-thymosins, small actin-binding peptides widely expressed in the developing and adult cerebellum. Cerebellum 1, 95-102.

Goodall, G.J., Dominguez, F., Horecker, B.L., 1986. Molecular cloning of cDNA for human prothymosin alpha. Proc Natl Acad Sci U S A 83, 8926-8928.

Hannappel, E., Huff, T., 2003. The thymosins. Prothymosin alpha, parathymosin, and beta-thymosins: structure and function. Vitam Horm 66, 257-296.

Hannappel, E., van Kampen, M., 1987. Determination of thymosin beta 4 in human blood cells and serum. J Chromatogr 397, 279-285.

He, X., Zhang, Y., Wu, X., Xiao, S., Yu, Z., 2011. Cloning and characterization of two ferritin subunit genes from bay scallop, Argopecten irradians (Lamarck 1819). Mol Biol Rep 38, 2125-2132.

Herrmann, D., Hatta, M., Hoffmeister-Ullerich, S., 2005. Thypedin, the multi copy precursor for the hydra peptide pedin, is a $\beta$-thymosin repeat-like domain containing protein. Mechanisms of development 122, 1183-1193.

Huff, T., Muller, C.S., Otto, A.M., Netzker, R., Hannappel, E., 2001. beta-Thymosins, small acidic peptides with multiple functions. Int J Biochem Cell Biol 33, 205-220. Kang, Y.J., Jo, J.O., Cho, M.K., Yu, H.S., Ock, M.S., Cha, H.J., 2011. Trichinella spiralis infection induces angiogenic factor thymosin beta4 expression. Vet Parasitol 
$181,222-228$.

Kasthuri, S.R., Premachandra, H.K., Umasuthan, N., Whang, I., Lee, J., 2013. Structural characterization and expression analysis of a beta-thymosin homologue (Tbeta) in disk abalone, Haliotis discus discus. Gene 527, 376-383.

Kumar, S., Gupta, S., 2011. Thymosin beta 4 prevents oxidative stress by targeting antioxidant and anti-apoptotic genes in cardiac fibroblasts. PLoS One 6, e26912.

Lee, H.R., Yoon, S.Y., Kang, H.B., Park, S., Kim, K.E., Cho, Y.H., Kim, S., Kim, C.W., Cho, B.J., Lee, W.J., Bang, S.I., Park, H., Cho, D., 2009. Thymosin beta 4 enhances NK cell cytotoxicity mediated by ICAM-1. Immunol Lett 123, 72-76.

Li, J., Zhang, Y., Xiang, Z.M., Xiao, S., Yu, F., Yu, Z.N., 2013. High mobility group box 1 can enhance NF-kappa B activation and act as a pro-inflammatory molecule in the Pacific oyster, Crassostrea gigas. Fish Shellfish Immun 35, 63-70.

Li, X., Zheng, L., Peng, F., Qi, C., Zhang, X., Zhou, A., Liu, Z., Wu, S., 2007a. Recombinant thymosin beta 4 can promote full-thickness cutaneous wound healing. Protein Expr Purif 56, 229-236.

Li, X.K., Zheng, L.S., Peng, F.W., Qi, C.Y., Zhang, X.G., Zhou, A.G., Liu, Z.W., Wu, S.H., 2007b. Recombinant thymosin beta 4 can promote full-thickness cutaneous wound healing. Protein Expres Purif 56, 229-236.

Liu, N., Lin, Z., Guan, L., Gaughan, G., Lin, G., 2014. Antioxidant enzymes regulate reactive oxygen species during pod elongation in Pisum sativum and Brassica chinensis. PLoS One 9, e87588.

Livak, K.J., Schmittgen, T.D., 2001. Analysis of relative gene expression data using 
real-time quantitative PCR and the 2(T)(-Delta Delta C) method. Methods 25, 402-408.

Malinda, K.M., Goldstein, A.L., Kleinman, H.K., 1997. Thymosin beta 4 stimulates directional migration of human umbilical vein endothelial cells. FASEB J 11, 474-481.

Nam, B.H., Seo, J.K., Lee, M.J., Kim, Y.O., Kim, D.G., An, C.M., Park, N.G., 2015. Functional analysis of Pacific oyster (Crassostrea gigas) beta-thymosin: Focus on antimicrobial activity. Fish Shellfish Immunol.

Nemolato, S., Cabras, T., Fanari, M.U., Cau, F., Fanni, D., Gerosa, C., Manconi, B., Messana, I., Castagnola, M., Faa, G., 2010. Immunoreactivity of thymosin beta 4 in human foetal and adult genitourinary tract. Eur J Histochem 54, e43.

Ottaviani, E., Franchini, A., Kletsas, D., Franceschi, C., 1996. Presence and role of cytokines and growth factors in invertebrates. Ital J Zool 63, 317-323.

Rebar, R.W., Miyake, A., Low, T.L., Goldstein, A.L., 1981. Thymosin stimulates secretion of luteinizing hormone-releasing factor. Science 214, 669-671.

Saelee, N., Noonin, C., Nupan, B., Junkunlo, K., Phongdara, A., Lin, X., Soderhall, K., Soderhall, I., 2013. beta-thymosins and hemocyte homeostasis in a crustacean. PLoS One 8, e60974.

Schillaci, D., Vitale, M., Cusimano, M.G., Arizza, V., 2012. Fragments of beta-thymosin from the sea urchin Paracentrotus lividus as potential antimicrobial peptides against staphylococcal biofilms. Ann N Y Acad Sci 1270, 79-85.

Selmi, A., Malinowski, M., Brutkowski, W., Bednarek, R., Cierniewski, C.S., 2012. 
Thymosin beta4 promotes the migration of endothelial cells without intracellular Ca2+ elevation. Exp Cell Res 318, 1659-1666.

Sosne, G., Qiu, P., Christopherson, P.L., Wheater, M.K., 2007. Thymosin beta 4 suppression of corneal NFkappaB: a potential anti-inflammatory pathway. Exp Eye Res 84, 663-669.

Spurney, C.F., Cha, H.J., Sali, A., Pandey, G.S., Pistilli, E., Guerron, A.D., Gordish-Dressman, H., Hoffman, E.P., Nagaraju, K., 2010. Evaluation of skeletal and cardiac muscle function after chronic administration of thymosin beta- 4 in the dystrophin deficient mouse. PLoS One 5, e8976.

Sritunyalucksana, K., Gangnonngiw, W., Archakunakorn, S., Fegan, D., Flegel, T.W., 2005. Bacterial clearance rate and a new differential hemocyte staining method to assess immunostimulant activity in shrimp. Dis Aquat Organ 63, 89-94.

Tang, Y.Q., Yeaman, M.R., Selsted, M.E., 2002. Antimicrobial peptides from human platelets. Infect Immun 70, 6524-6533.

Tian, Y.Y., An, L.J., Jiang, L., Duan, Y.L., Chen, J., Jiang, B., 2006. Catalpol protects dopaminergic neurons from LPS-induced neurotoxicity in mesencephalic neuron-glia cultures. Life Sci 80, 193-199.

Wang, K.J., Ren, H.L., Xu, D.D., Cai, L., Yang, M., 2008. Identification of the up-regulated expression genes in hemocytes of variously colored abalone (Haliotis diversicolor Reeve, 1846) challenged with bacteria. Dev Comp Immunol 32, $1326-1347$.

Wang, X.W., Zhang, X.W., Xu, W.T., Zhao, X.F., Wang, J.X., 2009. A novel C-type 
lectin (FcLec4) facilitates the clearance of Vibrio anguillarum in vivo in Chinese white shrimp. Dev Comp Immunol 33, 1039-1047.

Wu, L., Wu, X., 2009. Molecular cloning and expression analysis of a beta-thymosin homologue from a gastropod abalone, Haliotis diversicolor supertexta. Fish Shellfish Immunol 27, 379-382.

Xiao, Z., Shen, J., Feng, H., Liu, H., Wang, Y., Huang, R., Guo, Q., 2015. Characterization of two thymosins as immune-related genes in common carp (cyprinus carpio l.). Developmental \& Comparative Immunology.

Young, J.D., Lawrence, A.J., MacLean, A.G., Leung, B.P., McInnes, I.B., Canas, B., Pappin, D.J., Stevenson, R.D., 1999. Thymosin beta 4 sulfoxide is an anti-inflammatory agent generated by monocytes in the presence of glucocorticoids. Nat Med 5, 1424-1427.

Yu, F.X., Lin, S.C., Morrisonbogorad, M., Atkinson, M.A.L., Yin, H.L., 1993. Thymosin Beta-10 and Thymosin Beta-4 Are Both Actin Monomer Sequestering Proteins. J Biol Chem 268, 502-509.

Yu, Z., He, X., Fu, D., Zhang, Y., 2011. Two superoxide dismutase (SOD) with different subcellular localizations involved in innate immunity in Crassostrea hongkongensis. Fish Shellfish Immunol 31, 533-539.

Zhang, Y., He, X., Li, X., Fu, D., Chen, J., Yu, Z., 2011. The second bactericidal permeability increasing protein (BPI) and its revelation of the gene duplication in the Pacific oyster, Crassostrea gigas. Fish Shellfish Immunol 30, 954-963. 
Figure captions:

Fig 1: Multiple alignment and phylogenetic analysis of ChT $\beta 4$ with other members of the T $\beta 4$ family. (A) Multiple alignment of the ChT $\beta 4$ amino acid sequences. The conserved amino acid residues of these sequences are boxed. (B) The phylogenetic tree of $\mathrm{T} \beta 4$ sequences from vertebrates and invertebrates constructed by the neighbor-joining method. Node values represent the percent bootstrap confidence level derived from 1000 replicates. The bar (0.05) shows the genetic distance.

Fig 2: SDS-PAGE analysis of the purified recombinant ChT $\beta 4$ protein. Proteins were visualized by Coomassie Brilliant Blue staining.

Fig 3: Total hemocytes count (THC) of C. hongkongensis after injection with ChT $\beta 4$. Vertical bars represent the means \pm S.D. $(\mathrm{N}=10)$. Significant differences are indicated: $* p<0.05$.

Fig 4. Knockdown of ChT $\beta 4$ by dsRNA resulted in decreased bacterial number in vivo of oyster. (A). Effect of RNAi on ChT $\beta 4$ mRNA expression in hemocytes. The transcription levels of ChT $\beta 4$ in the dsChT $\beta 4$ injection control (dsGFP or PBS injection) groups were detected by qRT-PCR. (B). Decreased circulating THC after RNAi of ChT $\beta 4$. The asterisk indicates significant difference $(p<0.05)$.

Fig 5: Expression of ChT $\beta 4$ mRNA in C. hongkongensis. (A) Tissue distribution of ChT $\beta 4$ mRNA in various tissues: hemocytes, gonads, hearts, adductor muscles, mantles, gills and digestive glands. The vertical bars represent the means \pm S.D. (N=3). (B) Expression levels of ChT $\beta 4$ after bacterial challenge. Each bar represents 
the means \pm S.D. $(\mathrm{N}=5)$ from three different experimental repeats; significant differences are indicated: ${ }^{*} p<0.05$ and ${ }^{*} p p<0.01$.

Fig 6: ChT $\beta 4$ facilitating bacteria-clearance in oyster. V. alginolyticus was pre-coating with ChT $\beta 4$ or BSA, and then injected into the adductor muscle of oyster. The hemolymph of oyster were collected from pericardial cavity through the adductor muscle at $3,6,12$, and $24 \mathrm{~h}$ post-injection. After gradient dilution, the hemolymph was plated on LB agar plates overnight at $37^{\circ} \mathrm{C}$ to count the number of bacteria. Bacteria colonies were counted and then the residual percent of bacteria was determined. The asterisk indicates significant difference $(p<0.05)$.

Fig 7: Mean ROS production level (DCF fluorescence in arbitrary units of A.U.) of hemocytes after injection with ChT $\beta 4$. Vertical bars represented the means \pm S.D. (N $=5)$. The asterisk $(* p<0.05)$ indicates significant differences with the TBS control.

Fig 8: Effect of ChT $\beta 4$ on antioxidant enzymes under oxidative stress in hemocytes. Hemocytes were treated with $\mathrm{H}_{2} \mathrm{O}_{2}$ in presence and absence of ChT $\beta 4$ and (A) Catalase, (B) Cu/Zn-SOD and (C) GPX, mRNA expression were analyzed at 3, 6, 12 and $24 \mathrm{~h}$, respectively by qRT-PCR. Data represent the means \pm S.D. $(\mathrm{N}=5)$ of three separate experiments.

Fig 9: Expression pattern of ChT $\beta 4$ mRNA after tissue injury. Each bar represents the means \pm S.D. $(\mathrm{N}=5)$ from three different experimental repeats; significant differences are indicated: $* p<0.05$. 
Table 1 Sequences of primers used in this study

\begin{tabular}{|c|c|c|}
\hline Primer & Sequence $\quad(5-3)$ & Comment \\
\hline T $\beta 4 R 1$ & CACATGTTGCATTCATCCCTAGCCCT & 5' RACE of ChT $\beta 4$ \\
\hline $\mathrm{T} \beta 4 \mathrm{R} 2$ & GTTTCTTTGGTGGGTAGAGGGTTC & \\
\hline $\mathrm{T} \beta 4 \mathrm{~F} 1$ & GAAGGGCTAGGGATGAATGCAACATG & 3' RACE of ChT $\beta 4$ \\
\hline $\mathrm{T} \beta 4 \mathrm{~F} 2$ & GGACTCGCAATGACCCTTCTGTTT & \\
\hline UPM-Long & $\begin{array}{l}\text { CTAATACGACTCACTATAGGGCAAGCAGTGGT } \\
\text { ATCAACGCAGAGT }\end{array}$ & First PCR for 5' and 3' RACE \\
\hline UPM-short & CTAATACGACTCACTATAGGGC & \\
\hline NUP & AAGCAGTGGTATCAACGCAGAGT & Nested PCR for 5' and 3' RACE \\
\hline $\mathrm{T} \beta 4 \mathrm{~F} 3$ & AGCTGGATCC ATGAGTGATAAACCAGACGT & Vector for ChT $\beta 4-p E T 32 a$ \\
\hline T $\beta 4 \mathrm{R} 3$ & ACTGCTCGAGCTAGCCCTTCTTCTCTTGCT & \\
\hline $\mathrm{T} \beta 4 \mathrm{~F} 4$ & AACCAGACGTTAAAGAAGTC & Real-time-PCR of ChT $\beta 4$ \\
\hline $\mathrm{T} \beta 4 \mathrm{R} 4$ & AACAGAAGGGTCATTGCGAG & \\
\hline CuZnSOD-F & CСССТTCAACAAAGAGCACG & Real-time-PCR of ChCuZnSOD \\
\hline CuZnSOD-R & CATCAACATCGGCATGAATAAC & \\
\hline Catalase-F & CAGGAGCCTTCGGGTACTTT & Real-time-PCR of ChCatalase \\
\hline Catalase-R & GGTGTTGTTGCCCACTATGTC & \\
\hline GPX-F & TAAGTAACGCCGAAATTCCTCT & Real-time-PCR of ChGPX \\
\hline GPX-R & CCAGCAAATCTCGCCTAACTCT & \\
\hline $\mathrm{EF} 1 \alpha-\mathrm{F}$ & GCTCCACCCAACATCACCACTG & Real-time-PCR of EF1 $\alpha$ \\
\hline $\mathrm{EF} 1 \alpha-\mathrm{R}$ & ACGGATTTCCTTTACGGACACG & \\
\hline
\end{tabular}

"F" indicates forward primer and " $\mathrm{R}$ " indicates reverse primer. 
Crassostrea gigas

Crassostrea hongkongensis

Gallus gallus

Rattus norvegicus

Mus musculus

Homo sapiens

Bos taurus

Salmo salar

Danio rerio

Aplysia californica

Haliotis discus discus

Haliotis diversicolor supertex

strongylocentrotus purpuratus

Clustal Consensus

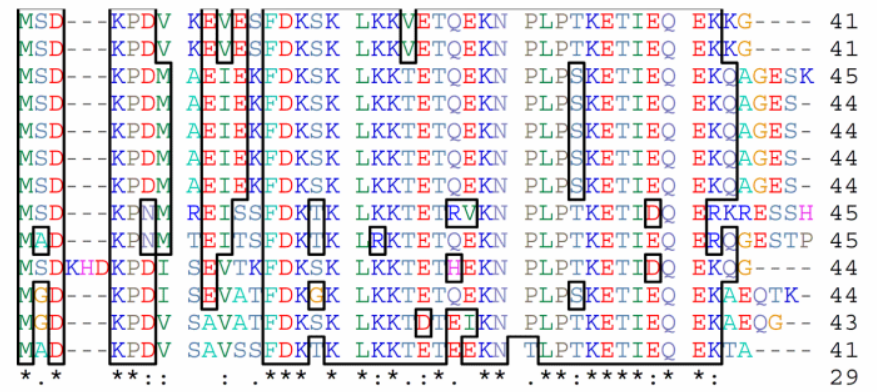

B

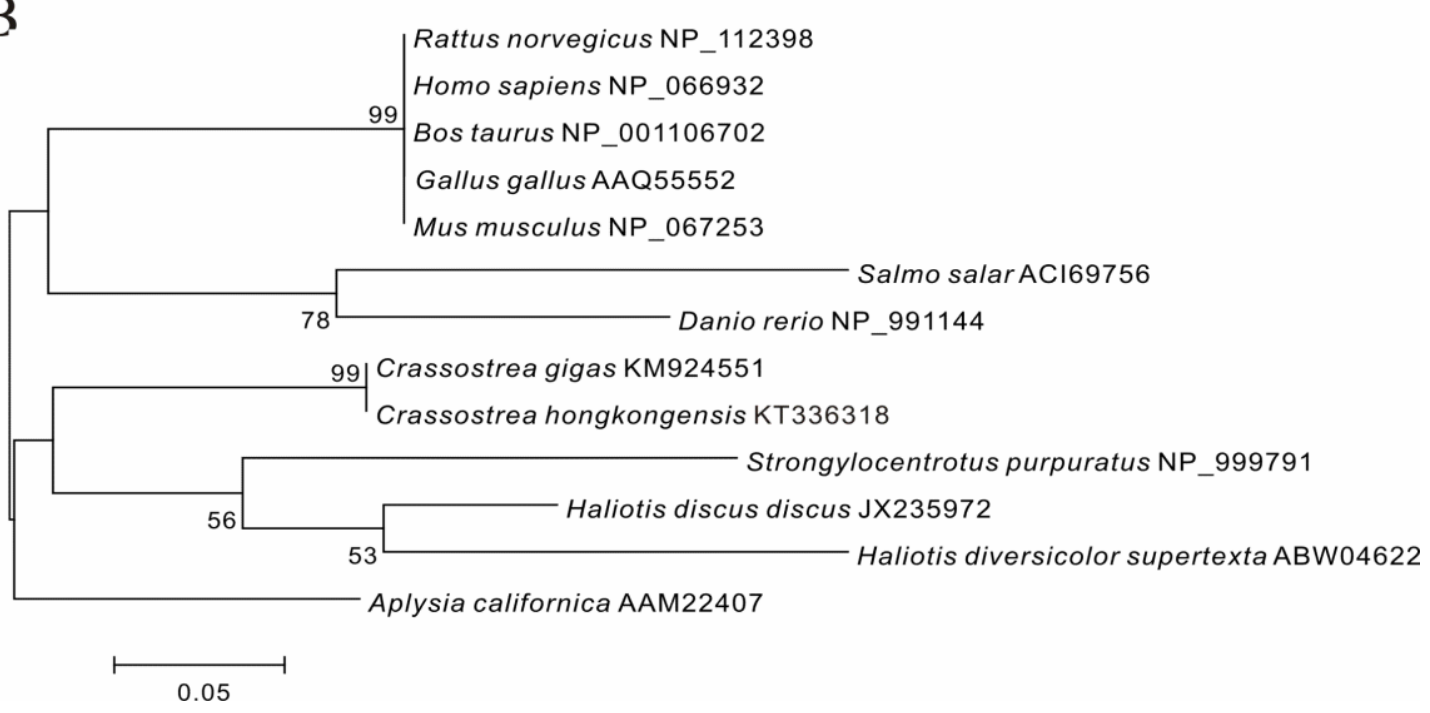


M ChT $\beta 4$-his

$66 \square$
$45 \square$
$35 \square$
$27 \square$
$14.4 \square$
9.5 


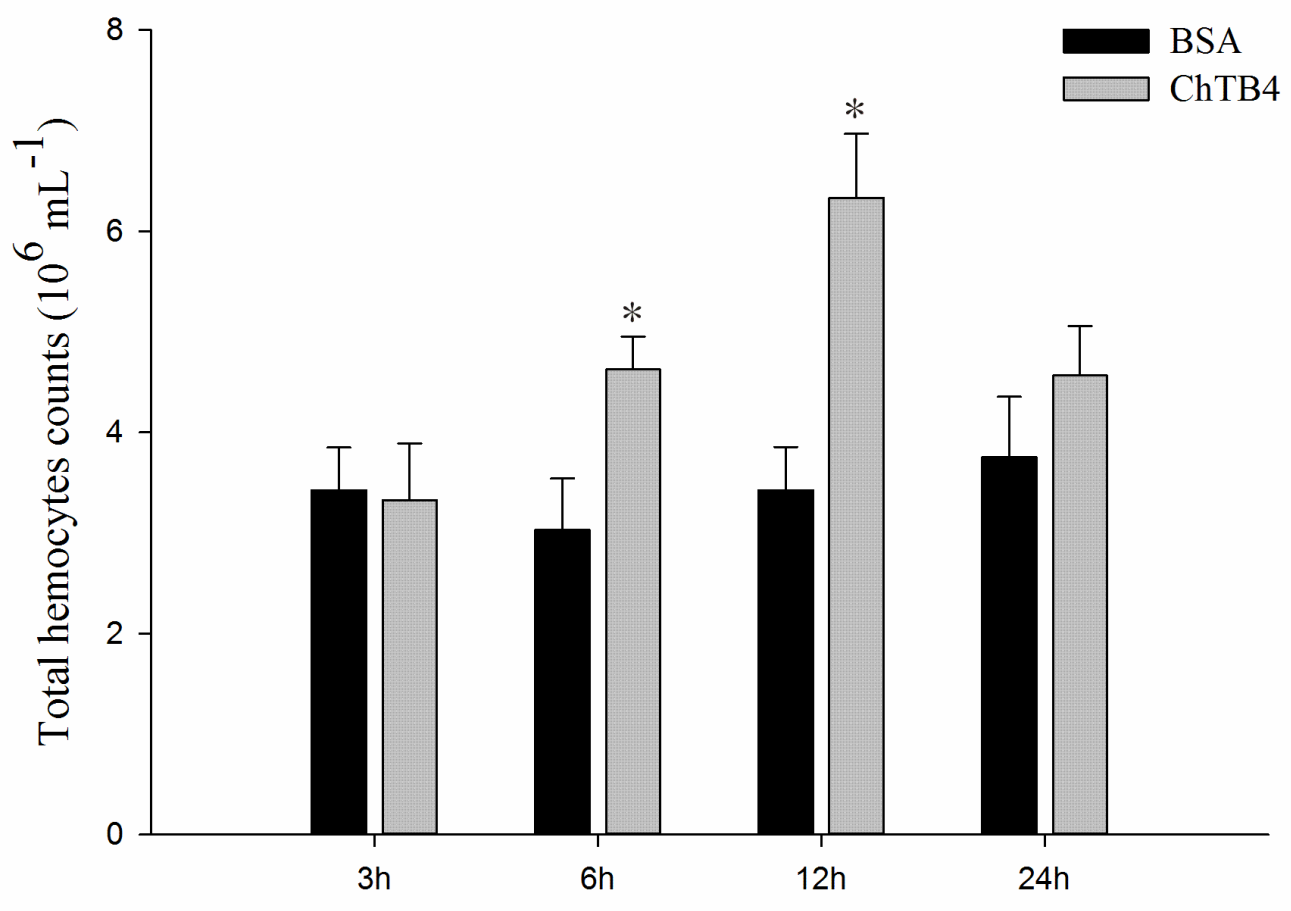



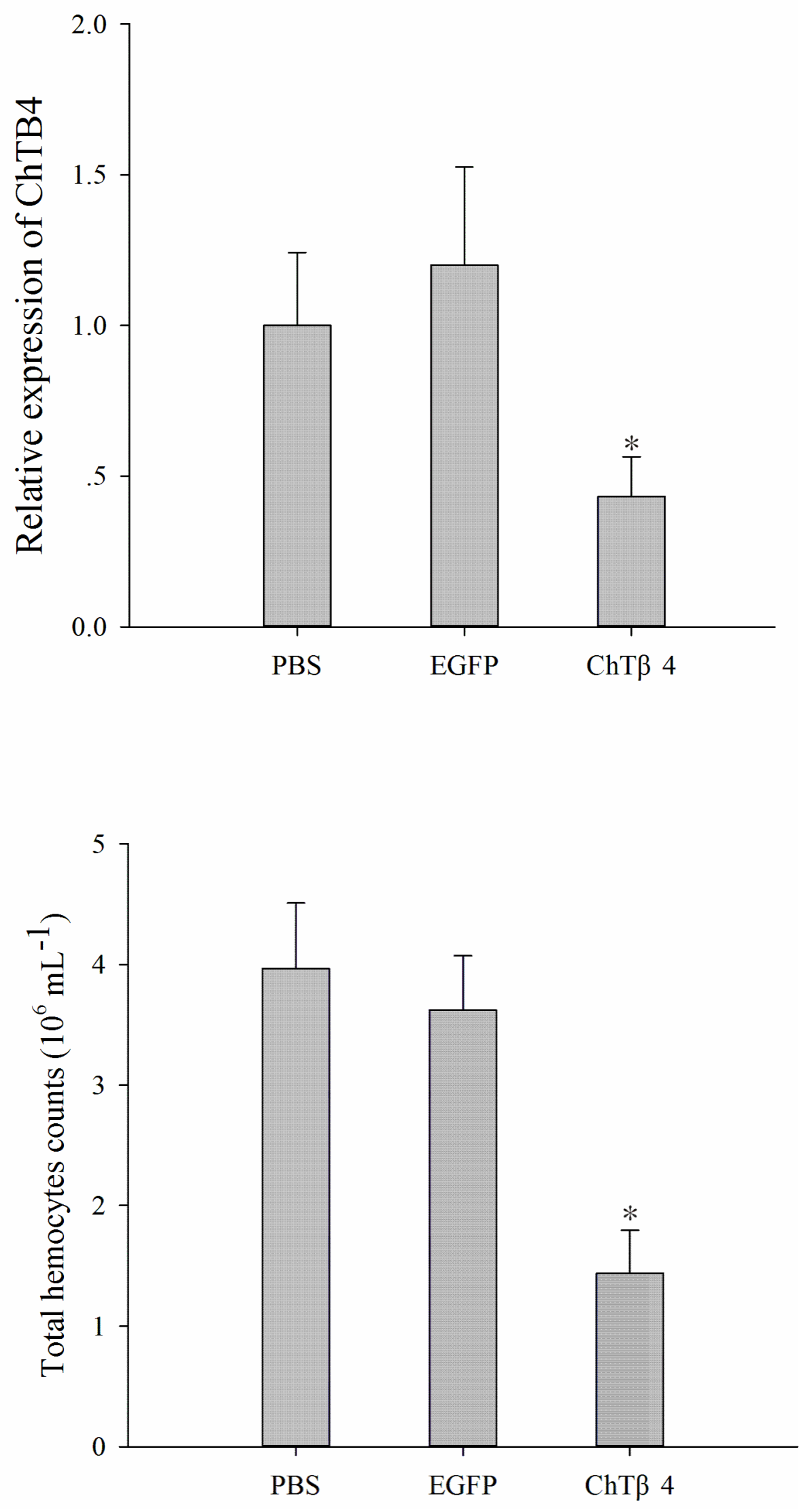
A
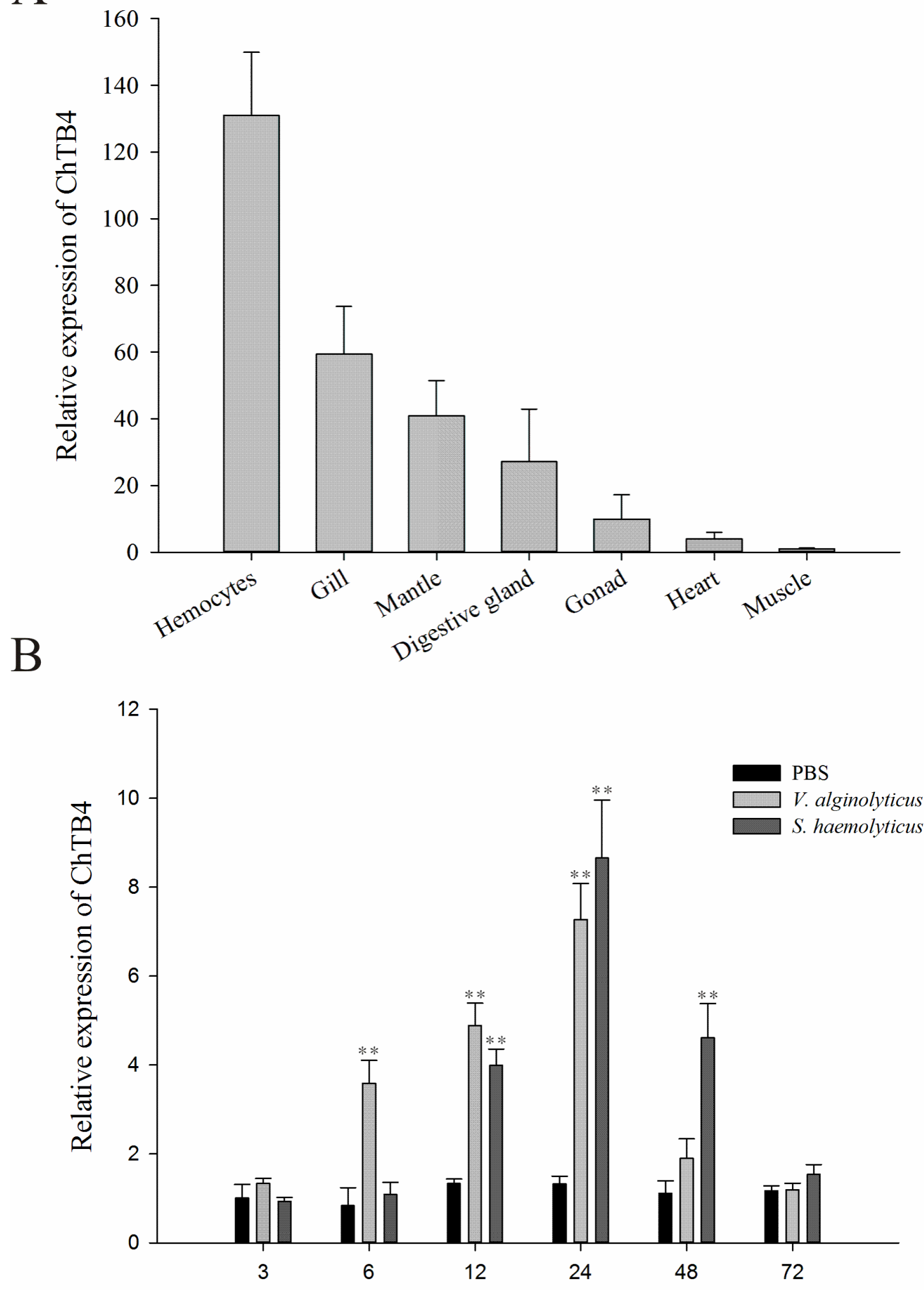

Time after bacterial challenge (h) 


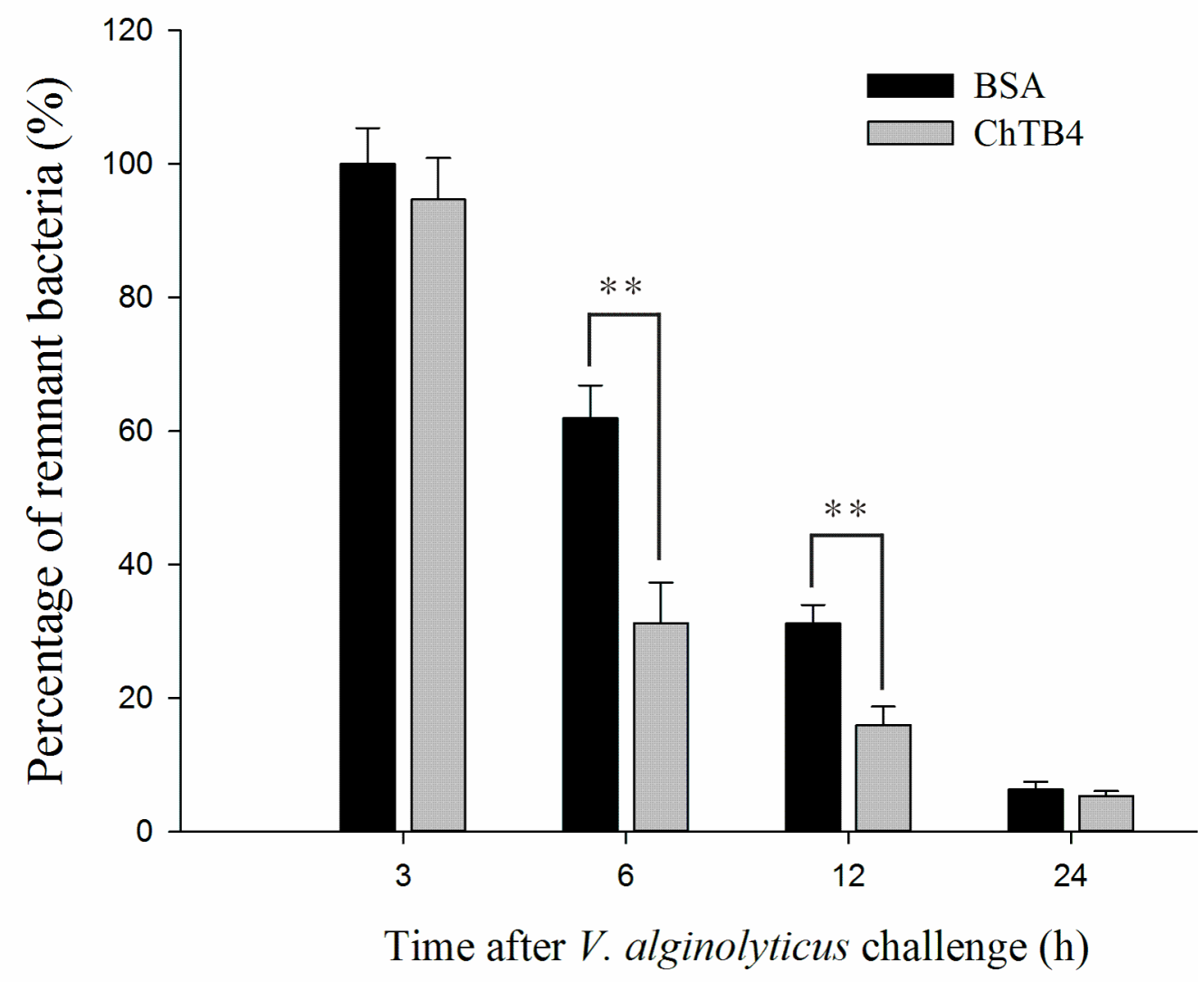




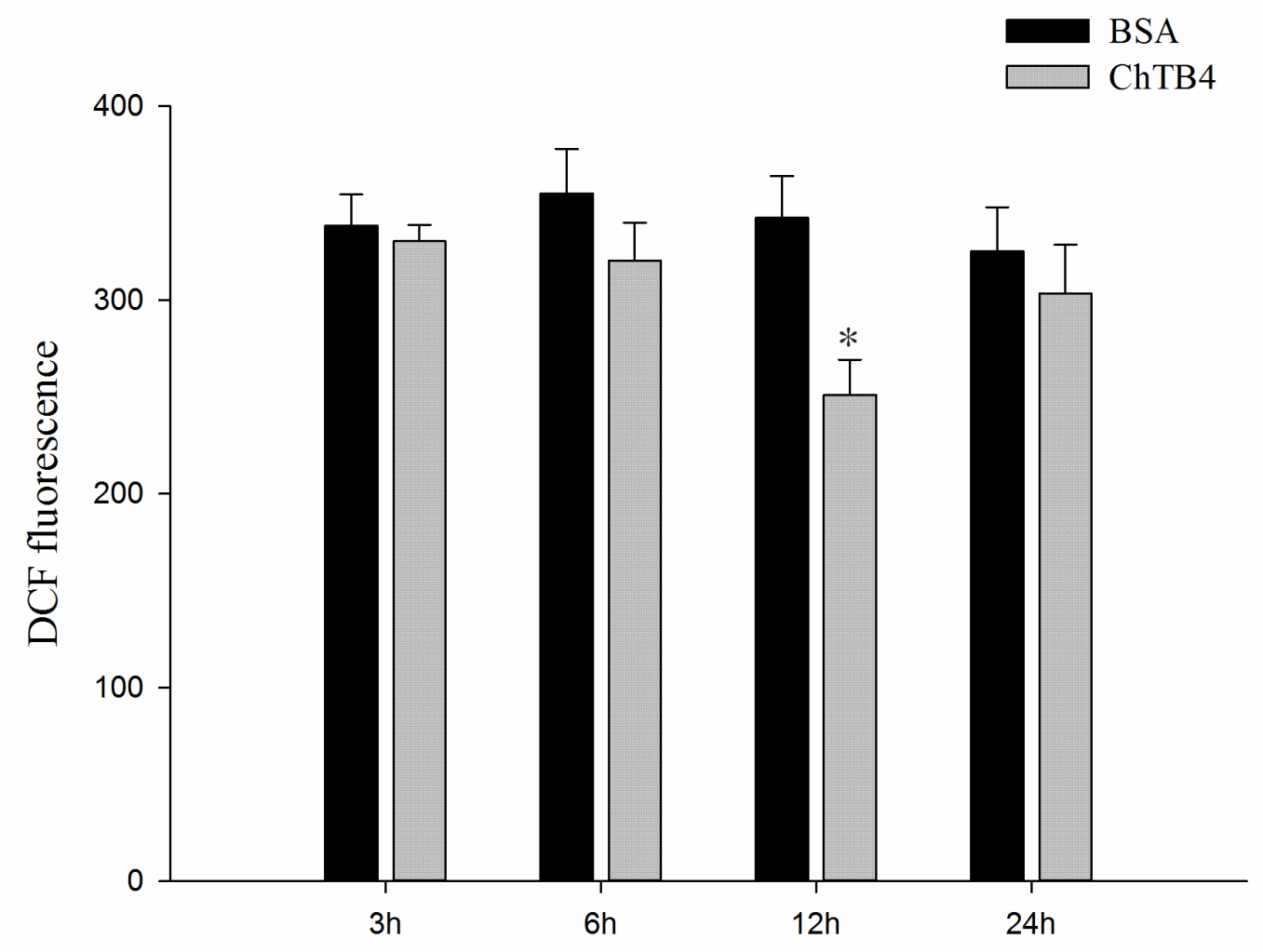




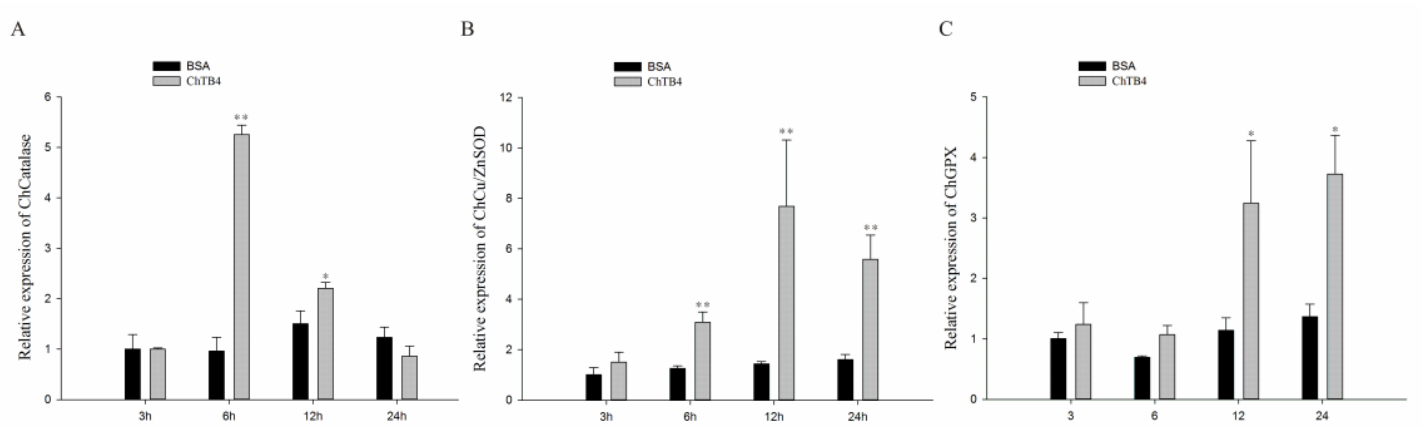




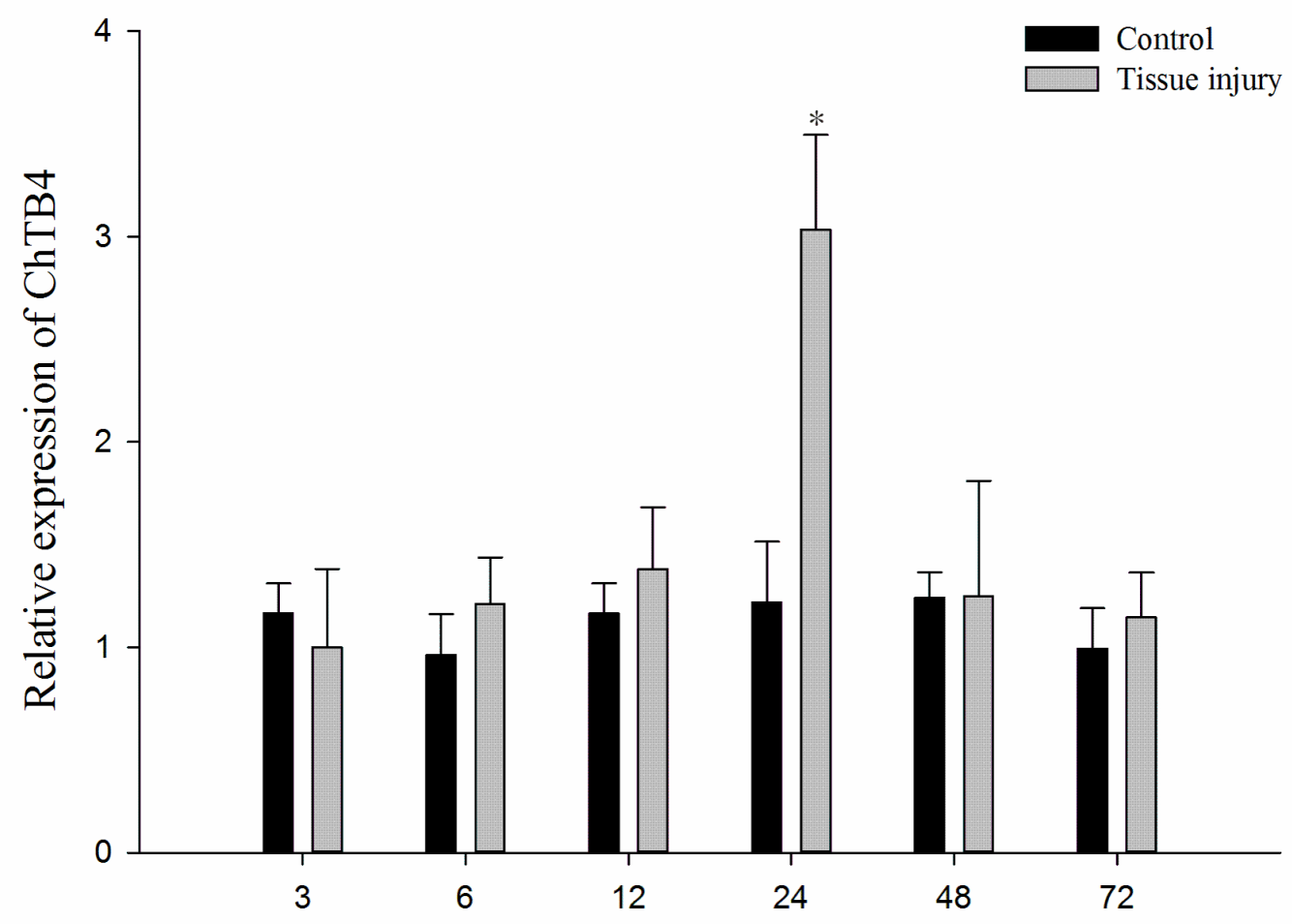

Time after tissue injury (h) 